\title{
IMPROVED TRAVELLING FIRES METHODOLOGY - iTFM
}

\author{
Egle Rackauskaite ${ }^{\mathrm{a}}$,Catherine Hamel $^{\mathrm{a}, \mathrm{b}}$, Guillermo Rein ${ }^{\mathrm{a}}$ \\ amperial College London, Department of Mechanical Engineering, UK \\ ${ }^{\mathrm{b}}$ University of Maryland, Department of Fire Protection Engineering, USA
}

\begin{abstract}
Current design codes and most of the understanding of behaviour of structures in fire are based on small enclosure fires. The World Trade Centre Tower fires in 2001 have highlighted the need of a more realistic design tools to represent fires in large compartments. Following the events Travelling Fires Methodology (TFM) has been developed by Stern-Gottfried and Rein to account for the travelling nature of fires. In this study the TFM is refined to account for more realistic fire dynamics. Equations are introduced to reduce the range of possible fire sizes. The analytical equations describing reducing far-field temperatures are presented. The concept of flame flapping is introduced to account for variation of temperatures in the near-field region due to natural fire oscillations. The need for more fundamental research and experimental evidence in large compartments for further development of and improvements on TFMis highlighted.
\end{abstract}

Keywords:travelling fires, steel, concrete, structural fire design, peak temperatures

\section{INTRODUCTION}

Current design codes use gas temperature-time curves which are based on small room fires. Consequently, most of the understanding of structural response in fire is based on the unrealistic assumption of uniform fire within the enclosure. While this may be of some validity for small enclosures (Stern-Gottfried et al. 2010), the observations of large accidental fires (e.g. World Trade Centre Tower fires in 2001) have shown that in large open-plan compartmentsfires do not cover the full area of the compartment. In such cases fires have been observed to travel from one part of the compartment to another with non-uniform temperature distribution (Stern-Gottfried \& Rein 2012a; Stern-Gottfried \& Rein 2012b). These fires are referred to as travelling fires.

Current design standards (e.g. Eurocodes) do not account for such fires. Clifton (Clifton 1996) was the first one to introduce the approach for development of temperature-time relationships which would consider travelling fires in 1996. However, since then it has not been developed further. Recently, extensive work has been done by Stern-Gottfried and Rein (Stern-Gottfried \& Rein 2012a; Stern-Gottfried \& Rein 2012b) who have developed a new design concept of the Travelling Fires Methodology (TFM). It considers non-uniform temperature distributions along the compartment and a wide range of fire sizes (burning floor area). The concept has already been applied by Engineering Consultant, Arup.

The focus of this study is the refinement of the TFM to account for more realistic fire dynamics and fire sizes. The proposed changes represent a crude fire model which can be used flexibly and adjusted to fit experimental data as it becomes available.

\section{TRAVELLING FIRES METHODOLOGY}

The Travelling Fires Methodology (TFM) framework(Stern-Gottfried \& Rein 2012b; SternGottfried \& Rein 2012a; Law et al. 2011) aims to incorporate the effect of non-uniform fires in large open-plan spaces. It does not supersede traditional design methods, but can be used in addition to them, and provides a range of possible fire dynamics.

TFM provides an approach for generation of gas temperature-time curves at the ceiling at any location in the compartment. It considers design fires to be composed of two moving regions: the nearfield (flames) and the far-field (smoke). Illustration of the two fields is shown in Fig.1. The nearfield represents the flames directly impinging on the ceiling and assumes the peak flame 
temperatures. The far-field model represents cooler smoke temperatures which decrease with radial distance away from the fire due to heat transfer and incremental mixing of hot gases with fresh air. Any structural element will experience cool far-field temperatures which correspond to pre-heating or cooling for much longer duration than the short hot near-field.In the present study the thermal descriptions of temperatures used in TFM, and the possible range of valid fire sizes are refined.

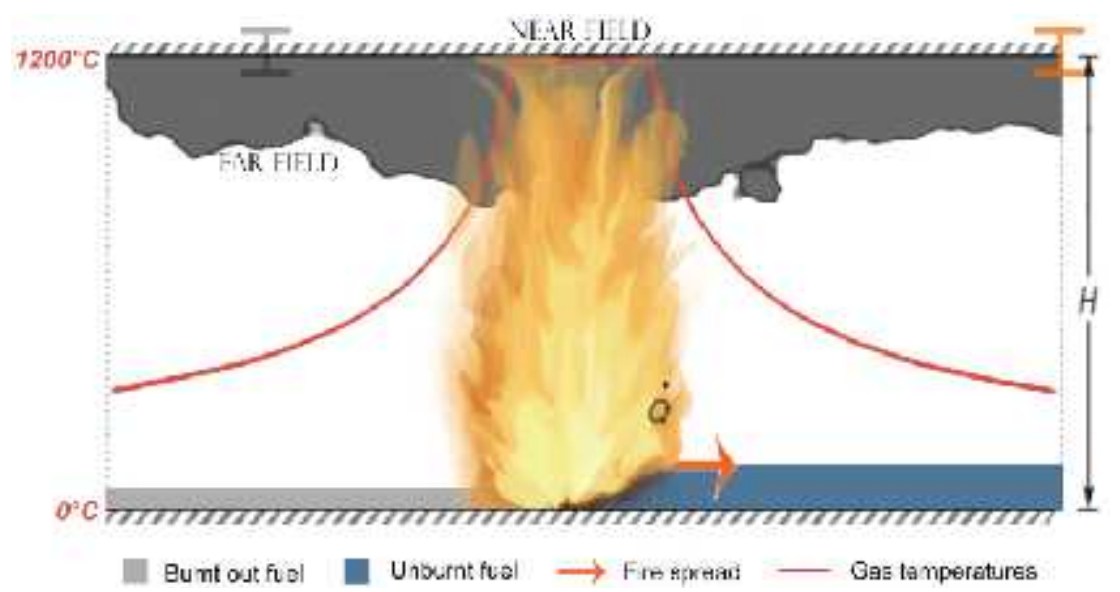

Fig.1 Illustration of a travelling fire and distribution of gas temperatures(Rackauskaite et al. 2015, CC BY-ND)

\section{REFINED TFM}

\subsection{Valid Range of Fire Sizes}

TFM is flexible in a way that, unlike Eurocodes, it is not limited to one fire type. It covers a wide range of fire sizes depending on the coverage of the total floor area from $1 \%$ to $100 \%$. The latter represents the whole compartment under uniform fire. The total fire duration depends on the fire size(Stern-Gottfried \& Rein 2012b).

However, it is unlikely that a very thin line fire across the whole width of the compartment or a whole floor fire (e.g. $2500 \mathrm{~m}^{2}$ ) in large compartments will occur. The reason for that may be the physical fire limitations such as available fuel load, fire spread rate and burning rate. The aim in the present study is to provide a more realistic representation of possible range of fire sizes which were not accounted for in the previous versions of TFM. This is necessary to reduce the family of fires passed to structural analysis, reduce computational time and neglect unrealistic results.

In the methodology a fire is assumed to be fuel controlled. Therefore, fuel load density and heat release rate are used as main design variables. Based on these values a local burning time needed for an area involved in fire to burn out completely is calculated (e.g. 19min) in Eq1. Local burning time multiplied by fire spread rate gives the distance the trailing edge of the fire would travel until the burn out at the ignition point. If the limits of the realistic fire spread rates (i.e. trailing edge) are known these can be used to compute the limiting sizes of possible fires as in Eq2:

$$
\begin{aligned}
t_{D} & =q_{I} / \dot{Q}^{\prime \prime} \\
L_{f, m} / m & =s_{m} / m \times t_{D}
\end{aligned}
$$

where $t_{b} \quad$ local burning time (s),

$q_{f} \quad$ fuel load density $\left(\mathrm{kJ} / \mathrm{m}^{2}\right)$,

$\dot{Q}^{\prime \prime} \quad$ heat release rate $\left(\mathrm{kW} / \mathrm{m}^{2}\right)$,

$L_{f, \min / \max }$ minimum or maximum possible fire size in terms of length along the fire path $(\mathrm{m})$,

$s_{\min / \max }$ minimum or maximum realistic fire spread rates in building fires $(\mathrm{m} / \mathrm{s})$.

There is very little available data on typical compartment fire spread rates. Thus, estimates were made based on the details provided in a number of fire test and real building fire investigation reports where the fires have been observed to travel (Thomas 1967; Kirby et al. 1994; Gann et al. 2013; Routley 1988). These fire spread rates were found to typically vary between 0.1 and 19.3 $\mathrm{mm} / \mathrm{s}$ (Rackauskaite et al. 2015). Thus, these values are suggested as minimum and maximum fire spread rates for determination of a valid range of fire sizes until more data becomes available. 
Clifton (Clifton 1996) in his design methodology assumed the values of 8.3 and $16.6 \mathrm{~mm} / \mathrm{s}$ for slow and fast fire spread respectively. These values agree well with the suggested range for the TFM. Based on the limitations from realistic fire spread rates, valid range of fire sizes can be described as below:

$$
f \quad L_{I, m} / L \times 100 \% \quad t_{1} \quad L_{T, m} \quad / L \times 100 \%
$$

where $L \quad$ length of the compartment.

For a heat release rate, fuel load density and fire path length of $500 \mathrm{~kW} / \mathrm{m}^{2}, 570 \mathrm{MJ} / \mathrm{m} 2$ and $50 \mathrm{~m}$, respectively, this would give a valid fire size range between $0.2 \%$ and $44 \%$. Much research on flame spread rates is still needed in order to gain a better understanding of fire dynamics. As new data and experimental evidence becomes available the range of possible fire spread rates in compartments can be updated as appropriate.

\subsection{Far-Field - The Analytical Solution}

In TFM the far-field model represents cooler smoke temperatures which decrease in radial distance away from the fire. Any available realistic correlation could be used to describe the far-field temperature depending on the accuracy required. Alpert's ceiling jet correlation (Alpert 1972) based on a set of experiments and initially created for sprinkler design is proposed in TFM to represent the far-field temperatures. However, in the most recent version (Stern-Gottfried \& Rein 2012b) TFM assumes the compartment to be divided into discrete nodes. The use of compartment floor discretization adds unnecessary complexity to the problem and reduces accuracy. In a parameter sensitivity study (Stern-Gottfried \& Rein 2012b) errors of up to $12.7 \%$ and $20 \%$ were found for peak bay temperatures and total burning durations respectively depending on the grid size chosen.

The most recent TFM version was simplified by developing the analytical expression for the farfield temperatures removing the errors which were imposed using the discrete method. The proposed equations can be used to rapidly calculate temperature variations at any time and location along the structural member in the compartment. Alpert's correlation (Alpert 1972), which the farfield model is based on, is shown below in Eq3.

$$
T_{m}-T_{\mathrm{w}}=5.38 \frac{(\dot{\mathrm{Q}} / \tau)^{2 / 3}}{H}
$$

where $T_{\max }$ gas temperature $\left({ }^{\circ} \mathrm{C}\right)$,

$T_{\infty} \quad$ room temperature $\left({ }^{\circ} \mathrm{C}\right)$,

$\dot{Q} \quad$ total heat release rate $\left(\mathrm{kW} / \mathrm{m}^{2}\right)$,

$r \quad$ radial distance away from the fire $(\mathrm{m})$,

$H \quad$ height of the compartment (m).

TFM assumes a uniform fuel load across the fire path $\left(q_{J}\right)$ and constant heat release rate $(\dot{Q})$. Also, the fire is defined by the specified surface area of burning fuel at any fixed time $\left(A_{I}\right)$. Therefore, based on this the total heat release rate can be calculated by the following equation:

$$
\dot{Q}=A_{I} \cdot \dot{Q}^{n}
$$

To consider fire growth and decay and to represent varying fire size at the beginning and end of the fire, respectively, the following equation can be used:

$$
A_{f}=L \cdot L_{t}^{*} \cdot W \cdot \dot{Q}^{\prime}
$$

where $L_{t}^{*} \quad$ varying dimensionless fire size which depends on the location of the leading edge,

$W \quad$ width of the compartment (m).

Dimensionless fire size $L^{*}$, fire spread rate $s[\mathrm{~m} / \mathrm{s}]$, local burning time $t_{D}[\mathrm{~s}]$ and location of the leading edge of the fire relative to the end of compartment where fire started $\dot{x}[\mathrm{~m}]$ can be calculated as follows:

$$
L^{*}=L_{T} / L
$$




$$
\begin{gathered}
s=L_{I} / t_{D} \\
t_{D}=q_{I}^{\prime} \dot{Q}^{\prime \prime} \\
\dot{x}=s \cdot t
\end{gathered}
$$

where $L_{f} \quad$ length of the area involved in fire $(\mathrm{m})$,

$t$ time (s).

Combining equations [3-9] we get a correlation for temperatures at the location $x(\mathrm{~m})$ and time $t(\mathrm{~s})$ of interest:

$$
\begin{gathered}
T_{I}(x, t)=T_{\mathrm{L}}+\frac{5.38}{H}\left(\frac{L L_{t}^{*} W \dot{Q}^{\prime \prime}}{x+0.5 L L_{t}^{*}-\dot{x}_{t}}\right)^{2 / 3} \\
T_{I}=T_{n}, i t\left\{\begin{array}{l}
T_{I}>T_{n} ; \\
x+0.5 L L_{t}^{*}-\dot{x}_{t} \leq 0.5 L_{I} .
\end{array}\right. \\
f \quad \dot{x} \leq L \rightarrow \dot{x}_{t}=\mathrm{s} \cdot t ; L_{t}^{*}=\min \left[L^{*},(s \cdot t) / L\right] \\
\dot{x}>L \rightarrow \dot{x}_{t}=\mathrm{L} ; \quad L_{t}^{*}=1+\left(L_{I}-s \cdot t\right) / L
\end{gathered}
$$

where $T_{f f} \quad$ far-field temperature $\left({ }^{\circ} \mathrm{C}\right)$,

$T_{n f} \quad$ near-field temperature $\left({ }^{\circ} \mathrm{C}\right)$,

$\dot{x}_{L} \quad$ location of the time dependant leading edge of the fire $(\mathrm{m})$.
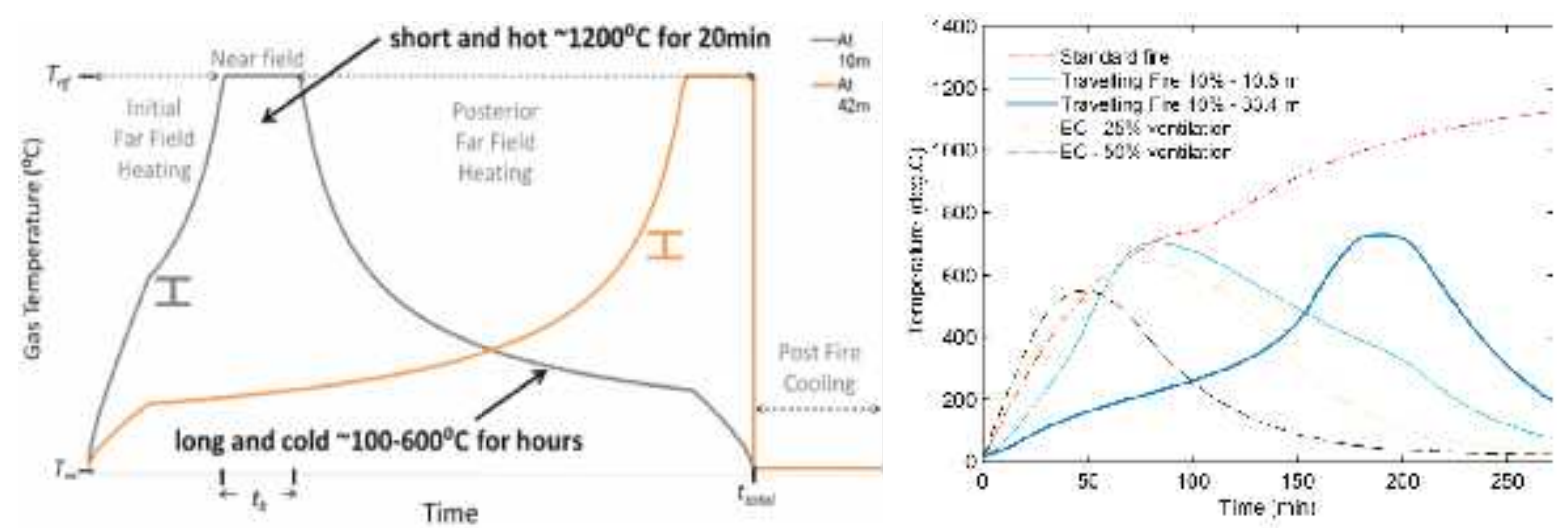

Fig.2 Near-field and far-field exposure duration at an arbitrary point and at the far end of the compartment (Stern-Gottfried \& Rein 2012b) (left); example temperature development within a steel beam with $60 \mathrm{~min}$ fire protection for various fire exposures, assumed compartment dimensions - 24 x 40 x $3.6 \mathrm{~m}$ (right)

Conditions described by Eq11 represent the near-field temperature. It implies that far-field temperatures cannot exceed the chosen maximum flame temperature and sets it to a constant value. It also sets the near-field temperature value for the whole length of the area involved in fire. Eq12 and Eq13 are used to define varying fire size and location of the leading edge based on whether fire is still increasing in size or is at its maximum size (Eq12) or has reached the far end of thecompartment and is decaying (Eq13). Sample of resulting gas temperature fields experienced by structural members at two locations within a typical compartment and temperature development within 60 min protected steel beam are shown in Fig.2.

\subsection{Near-Field - Flame Flapping}

In TFM the near-field represents the flames directly impinging on the ceiling and assumes the peak flame temperatures. Such temperatures in various building fires and experiments have been measured in the range of 800-1200 ${ }^{\circ} \mathrm{C}$ (Thomas 1974; Drysdale 1998; Lennon \& Moore 2003; Kirby et al. 1994). To stay on the conservative side TFM described by Stern-Gottfried and Rein (SternGottfried \& Rein 2012b) assumed the near-field temperature to be $1200^{\circ} \mathrm{C}$.

In reality due to the lateral fluctuations of the flames on the ceiling gas temperatures are typically continuously varying between the observed temperatures of 800 and $1200^{\circ} \mathrm{C}$ (Quintiere 1998; 
Santoni et al. 2002; Crauford 1984). In TFM this is referred to as flame flapping. For this reason structural members will actually experience lower average temperatures rather than the peak temperatures observed in fires. There is no experimental evidence from large compartment fires or correlations based on which the reduced near-field temperature could be related to either fire size or oscillations. The angle $\theta$ from the main axis of the flame, as shown in Fig.3, is chosen to represent the length on the ceiling over which fluctuations of the impinging flame occur.

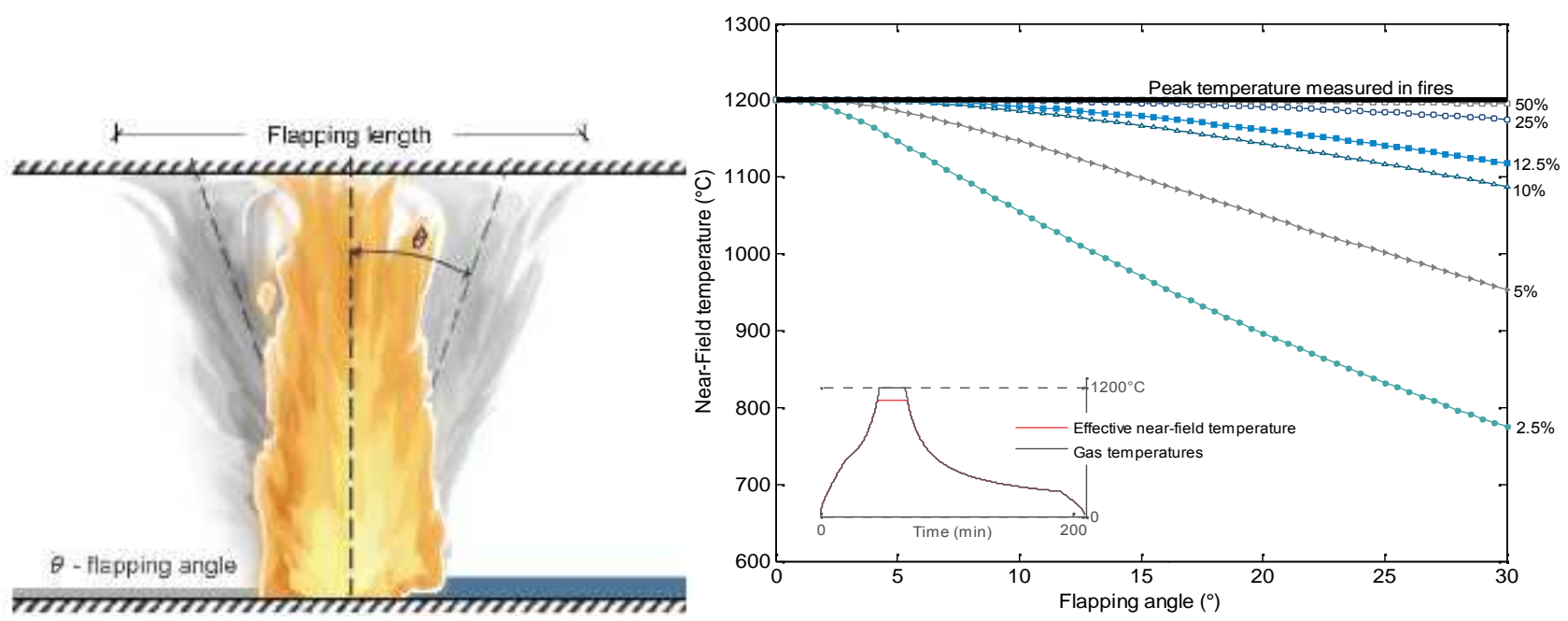

Fig.3 Representation of the flapping length on the ceiling (Rackauskaite CC BY-ND) (left); and variation of reduced near-field temperature with flapping angle and fire size(right) (Rackauskaite et al. 2015)

For the updated version of TFM the flapping angle of $\pm 6.5^{\circ}$ was chosen (Rackauskaite et al. 2015) based on results from Quintiere et al. (Quintiere et al. 1981) experiments.In this TFM the flapping angle as identified previously is used to calculate the ceiling length over which the impinging fire fluctuations occur. Over this length the average temperature is calculated including both far-field and peak near-field temperatures $\left(1200^{\circ} \mathrm{C}\right)$. This represents the mixing of cooler smoke with fluctuating flame resulting in a lower near-field temperature. The newly calculated reduced nearfield temperature is used to generate travelling fire time-temperature curves instead of a fixed peak value of $1200^{\circ} \mathrm{C}$. The equation used to calculate the reduced near-field temperature due to flapping is shown below and is derived from Alpert's ceiling jet correlation.

$$
T_{f}=T_{\mathrm{x}}+\frac{T_{n}\left(2 T_{x 1}+L_{I}\right)-2 T_{\mathrm{xx}} \times r_{x z}}{f}+\frac{32.28 \dot{Q}^{2 / 3}}{H \times f}\left(\left(r_{2}\right)^{1 / 3}-{r_{x 2}}^{1 / 3}\right)
$$

where

$$
\begin{gathered}
r_{2}=f^{\prime} 2 \\
r_{x 2}=m \quad\left(L_{T} / 2, T_{0}\right) \\
r_{x 1}=\max \left(0, T_{0}-L_{I} / 2\right) \\
T_{n}=1200^{\circ} \mathrm{C} \\
T_{0}=\left(\frac{5.38}{H\left(T_{n}-T_{\mathrm{x}}\right)}\right)^{3 / 2}
\end{gathered}
$$

where $f \quad$ flapping length (m).

It can be seen in Fig. 3 that the concept of flapping leads to the reduced near-field temperatures, depending on a fire size, in the range of $800-1200^{\circ} \mathrm{C}$ as observed in real fires. With increasing flapping angle the resulting temperature for each fire size decreases as well. This is due to the mixing of direct flames and growing proportion of cooler smoke with increasing flapping length. However, this is just a crude approximation and more research on peak flame temperatures in relation to fire size in large enclosures is necessary. 


\section{CONCLUSIONS}

In this study the Travelling Fires Methodology developed by Stern-Gottfried and Rein to account for the travelling nature of fires has been refined:

- Introduced limitation to the range of possible fire sizes eliminates the unrealistic fire coverage areas and thus the computational time required. Limitation is based on fire spread rates observed in experiments and real fires. However, more research on realistic fire spread rates is necessary to get a more realistic range.

- Analytical correlation presented for generation of gas time-temperature curves can be easily calculated with any mathematical tool.

- Introduction of flapping to account for flame fluctuations and mixing with cooler smoke leads to the reduced near-field temperatures for smaller fire sizes. They cover a range between 800 $1200^{\circ} \mathrm{C}$ observed in real building fires.

The proposed changes represent a crude fire model which can be used flexibly. More experimental evidence in large compartments is necessary for further development and improvements.

\section{ACKNOWLEDGMENTS}

The research has been funded by the Engineering and Physical Sciences Research Council EPSRC (CASE Quota award) and Ove Arup and Partners Limited, and the SFPE Educational \& Scientific Foundation.

\section{REFERENCES}

Alpert, R.L., 1972. Calculation of response time of ceiling-mounted fire detectors. Fire Technology, 8(3), p.181-195.

Clifton, C.G., 1996. Fire Models for Large Firecells, HERA Report R4-83

Crauford, N.L., 1984. The structure of an unconfined buoyant turbulent diffusion flame. University of Southampton.

Drysdale, D.D., 1998. A Introduction to fire Dynamics.

Gann, R.G. et al., 2013. Reconstruction of the Fires and Thermal Environment in World Trade Center Buildings 1, 2, and 7. Fire Technology, 49(3), p.679-707.

Kirby, B.R. et al., 1994. Natural fires in large scale compartments - A British Steel technical, Fire Research Station collaborative project.

Law, A. et al., 2011. The influence of travelling fires on a concrete frame. Engineering Structures, 33(5), p.1635-1642.

Lennon, T. \& Moore, D., 2003. The natural fire safety concept-full-scale tests at Cardington. Fire Safety Journal, 38(7), p.623-643.

Quintiere, J.G., 1998. Principles of Fire Behaviour, Cengage Learning.

Quintiere, J.G., Rinkinen, W.J. \& Jones, W.W., 1981. The Effect of Room Openings on Fire Plume Entrainment. Combustion Science and Technology, 26(5-6), p.193-201.

Rackauskaite, E. et al., 2015. Improved formulation of travelling fires and application to concrete and steel structures. Structures, (in press)

Routley, J.G., 1988. Interstate Bank Building Fire, Los Angeles.

Santoni, P.-A., Marcelli, T. \& Leoni, E., 2002. Measurement of Fluctuating Temperatures in a Continuous Flame Spreading Across a Fuel Bed Using a Double Thermocouple Probe. Combustion and Flame, 131, p.47-58.

Stern-Gottfried, J. et al., 2010. Experimental review of the homogeneous temperature assumption in postflashover compartment fires. Fire Safety Journal, 45(4), p.249-261.

Stern-Gottfried, J. \& Rein, G., 2012a. Travelling fires for structural design-Part I: Literature review. Fire Safety Journal, 54, p.74-85.

Stern-Gottfried, J. \& Rein, G., 2012b. Travelling fires for structural design-Part II: Design methodology. Fire Safety Journal, 54, p.96-112.

Thomas, P.H., 1974. Fires in Enclosures. In P. L. Blackshear, ed. Heat transfer in fires: thermophysics, social aspects, economic impact. Washington: Building Research Establishment, p.13.

Thomas, P.H., 1967. Some Aspects of the Growth and Spread of Fire in the Open. Forestry, 40(2), p.139164. 